\title{
Mindfulness affects stress, ghrelin, and BMI of obese children: a clinical trial
}

\author{
Mardia López-Alarcón ${ }^{1}$, Jessie N Zurita-Cruz' ${ }^{1}$ Alonso Torres-Rodríguez², Karla Bedia-Mejía', Manuel Pérez-Güemez', \\ Leonel Jaramillo-Villanueva ${ }^{3}$, Mario E Rendón-Macías ${ }^{4}$, Jose R Fernández ${ }^{5}$ and Patricia Martínez-Maroñas ${ }^{2}$ \\ ${ }^{1}$ Unidad de Investigación Médica en Nutrición, Hospital de Pediatría, Centro Médico Nacional Siglo XXI, Instituto Mexicano del Seguro Social, \\ México, Mexico \\ ²Escuela Española de Desarrollo Transpersonal, Madrid, España \\ ${ }^{3}$ Departamento de Psiquiatría, Hospital de Pediatría, Centro Médico Nacional Siglo XXI, Instituto Mexicano del Seguro Social, México, Mexico \\ ${ }^{4}$ Universidad Panamericana, Facultad de Ciencias de la Salud, Escuela de Medicina, México, Mexico \\ ${ }^{5}$ Departments of Nutrition Sciences and Biostatistics, University of Alabama at Birmingham, Birmingham, Alabama, USA \\ Correspondence should be addressed to M López-Alarcón: mardyalo@hotmail.com
}

\begin{abstract}
Childhood obesity is associated with stress. However, most treatment strategies include only dietary and physical activity approaches. Mindfulness may assist in weight reduction, but its effectiveness is unclear. We assessed the effect of mindfulness on stress, appetite regulators, and weight of children with obesity and anxiety. A clinical study was conducted in a pediatric hospital. Eligible children were 10-14 years old, BMI $\geq 95$ th percentile, Spence anxiety score $\geq 55$, and who were not taking any medication or supplementation. Participants were assigned to receive an 8-week conventional nutritional intervention (CNI) or an 8-week mindfulness-based intervention plus CNI (MND-CNI). Anthropometry, body composition, leptin, insulin, ghrelin, cortisol, and Spence scores were measured at baseline and at the end of the intervention. Anthropometry was analyzed again 8 weeks after concluding interventions. Log-transformed and delta values were calculated for analysis. Thirty-three MND-CNI and 12 CNI children finished interventions; 17 MND-CNI children accomplished 16 weeks. At the end of the intervention, significant reductions in anxiety score $(-6.21 \pm 1.10)$, BMI $\left(-0.45 \pm 1.2 \mathrm{~kg} / \mathrm{m}^{2}\right)$, body fat $(-1.28 \pm 0.25 \%)$, ghrelin $(-0.71 \pm 0.37$ $\mathrm{pg} / \mathrm{mL})$, and serum cortisol $(-1.42 \pm 0.94 \mu \mathrm{g} / \mathrm{dL})$ were observed in MND-CNI children. Changes in anxiety score, ghrelin, and cortisol were different between groups $(P<0.05)$. Children who completed 16 weeks decreased BMI after intervention $\left(-0.944 \pm 0.20 \mathrm{~kg} / \mathrm{m}^{2}\right.$, $P<0.001)$ and remained lower 8 weeks later $\left(-0.706 \pm 0.19 \mathrm{~kg} / \mathrm{m}^{2}, P=0.001\right)$. We concluded that mindfulness is a promising tool as an adjunctive therapy for childhood obesity. However, our findings need confirmation in a larger sample population.
\end{abstract} Key Words

- mindfulness

- children

- obesity

- stress

- ghrelin

\section{Introduction}

Pediatric obesity is a pathological condition that leads to important health consequences in childhood and later life $(1,2)$. In addition to diet and sedentary behavior, psychological factors such as stress, depression, and anxiety associated with obesity have been found in up to $86 \%$ of cases $(2,3)$. Most treatment strategies in children aim to improve life styles through dietary or physical activity approaches only. In the last decade, several studies have included psychological interventions to prevent or reduce obesity, most of them in adults and with unclear results.

The mechanisms involved in the association between stress and obesity have not been fully described. Scientific evidence suggests that individuals under chronic stress lose the ability of conscientious eating, resulting in a sustained increase in the consumption of calorie-dense food $(4,5)$.

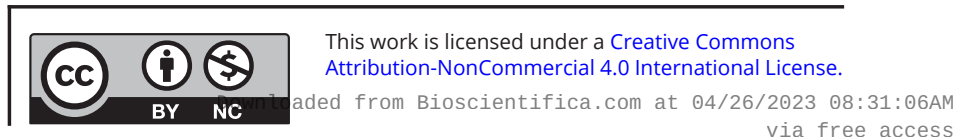


In fact, most of the eating disorders identified in children, such as emotional eating (eating in absence of hunger), binge eating (eating a large amount of food in a short period of time), external eating (eating as a result of external prompts, such as those in TV advertisements), and mindless eating (unconscious eating as when eating in front of a computer screen), share a common scenario that is an adaptation in response to stress (6). Importantly, obese patients with these eating disorders have demonstrated a poor response to conventional weight loss interventions (6). Therefore, the search for efficient strategies to reduce stress in children with obesity is essential.

Mindfulness is a psychological technique focused on attention, awareness, and meditation that has been successfully used to reduce the stress associated with diseases such as cancer, multiple sclerosis, attention deficit disorder and anorexia nervosa, amongst others ( 7 , 8,9 ). It has been proposed that mindfulness could be a potential adjuvant therapy to reduce body weight (10). The rationale is that, by reducing stress, mindfulness may affect cortisol (11), which secondarily may affect some hormones involved in appetite regulation such as insulin (12), leptin and ghrelin (13). However, the results of these investigations are controversial $(7,8,9,10,11,12,13)$.

Most of the studies conducted to date have separately analyzed the influence of mindfulness in different outcomes related to obesity, such as eating behavior $(14,15)$, subjective stress $(16)$, serum cortisol $(17,18)$, or body weight $(19,20)$ in adult populations with conflicting results. To the best of our knowledge, only a few studies have been conducted in pediatric groups. One of these pediatric studies reported an association between dispositional mindfulness (non-trained mindfulness characteristics) and eating behavior, since it inversely correlated with calorie intake when eating in the abscence of hunger (21). Similar results were detected in another descriptive study, which reported that dispositional mindfulness was associated with subjective stress, but not with cortisol response (22). Later, Shomaker et al., with an intervention design, found that a mindfulness program decreased depressive symptoms and insulin resistance in overweight girls at risk of type 2 diabetes (12). Changes in body weight were not analyzed in any of these studies.

The main aim of our study was to determine the effect of an 8-week mindfulness-based intervention on stress, appetite regulators, and body weight of school children with coexisting obesity and anxiety, under the hypothesis that mindfulness will help to improve the response to dietary restriction, likely by decreasing stress.
Secondarily, we evaluated the effect on relapse by conducting anthropometric investigations 8 weeks after concluding the 8-week intervention period.

\section{Material and methods}

\section{Study population}

A clinical study was conducted in the Medical Nutrition Research Unit in a Pediatric Hospital of the Instituto Mexicano del Seguro Social (IMSS) in Mexico City. The research protocol was authorized by the IMSS National Committee of Scientific Research (R-2017-785-096) and registered in ClinicalTrials.gov (clinicaltrials.gov NCT03495310).

Selected children were recruited from four elementary and middle schools located in the neighborhood of the Research Unit. Because small groups permit more efficient mindfulness sessions, interventions were carried out in two phases. For the first phase, we recruited children in January-March and the intervention sessions were held in April-May 2018; for the second phase, children were recruited in June-July and the intervention sessions were held in September-October 2018.

Given that a reduction of $9.4 \pm 11 \mathrm{nmol}$ cortisol (23) and $1.8 \pm 1.7 \mathrm{~kg}$ body weight (10) were reported in adults exposed to mindfulness interventions, we used these values to estimate sample size. Considering an $80 \%$ power and alpha 0.05 , the estimated sample was 22 children; $20 \%$ was added to replace dropouts giving a final sample of 27 children per group.

\section{Study design}

Field workers visited participant schools to conduct anthropometry and to apply an anxiety questionnaire to children 10-17 years old, from both sexes, in order to identify potential candidates. Eligible children were those with BMI $\geq 95$ percentile (24), a total Spence anxiety score $\geq 55$ (25), without clinical evidence of chronic diseases, and not taking any medication or supplementation. The parents of children identified with coexisting obesity and anxiety were asked to attend an informative meeting where they were invited to participate. Written informed parental consent, in addition to the assent of the children, were obtained from all participants. Those who agreed to participate were assigned to a group that received an 8-week mindfulness intervention along with a conventional nutritional intervention (MND-CNI) or to 
a group that received an 8-week conventional nutritional intervention (CNI) only. Although a randomized trial was planned and randomization was generated through an electronic program (26), once the protocol procedures were explained to parents, most made being assigned to the MND-CNI group a condition of participation, resulting in an imbalanced sample size.

After being assigned to a group, children were asked to attend the Research Unit at 07:00 h after 8-10 h of fasting to determine weight, height and body composition (percentage body fat), and to take blood samples to measure serum insulin, leptin, ghrelin, and cortisol. Materials and instructions were provided for the sampling of saliva at home to determine the cortisol response curve. The same procedures were repeated after the 8-week intervention period. Anthropometry was repeated again 8 weeks after finishing the 8-week intervention period to assess weight recovery or relapse.

\section{Interventions}

\section{Conventional nutrition intervention (CNI)}

Written dietary recommendations attached to the World Health Organization guidelines were prescribed. Such recommendations included a hypocaloric diet consistent with a $700 \mathrm{kcal}$ restriction of the usual dietary intake (27). Children and at least one parent or caregiver attended half-hour sessions, once a week, to revise and solve questions about diets. For the MND-CNI group, this halfhour dietary activity was offered immediately before the 2-h mindfulness sessions.

\section{Mindfulness intervention (MND)}

The mindfulness intervention was provided by two certified mindfulness consultants using the method developed for children by the 'Escuela Española de Desarrollo Transpersonal' (Mindfulness-Based Stress ReductionEat Mindful) (28) once permission was granted. The intervention for children consisted of instructor guided 2-h sessions, once a week, for 8 weeks. Sessions included interactive activities and guided discussions to teach standard mindfulness skills to be used as simple practices in daily life. Mindfulness activities during sessions included exercises to: (i) practice meditation, (ii) learn different types of breathing, (iii) improve body awareness using body scan and organ senses scanner techniques, (iv) understand the transient character of emotions, (v) acquire abilities to observe and release thoughts, (vi) use the semaphore technique to detect those anxiety signals that provoke impulsive reactions, and (vii) practice conscious eating. At the end of each session, a short homework exercise was assigned to help children to apply mindfulness skills to daily life.

At least one parent or caregiver of each child was asked to attend the 2 -h mindfulness sessions, delivered in parallel with the sessions provided to the children, but in a different room, to learn mindfulness attitudes and reinforce the information given to children.

\section{Measurements}

\section{Anthropometry}

Weight and height were measured with standard procedures using electronic scales (InBody 230, model MW160, Tokyo, Japan) and fixed stadiometers (Holtain Limited). BMI z-scores were calculated with Epi-Info software (EPI-INFO 2000, release 3.2.2). Percentage body fat was measured by bioelectrical impedance (InBody 230, model MW160).

\section{Anxiety symptoms and perceived stress}

We used the Spence self-report questionnaire, which is regularly used in the Psychiatry Department of our hospital, to detect subjective stress and anxiety. The questionnaire consists of 44 questions separated into seven subscales designed to assess: (a) social phobia, (b) panic disorder, (c) agoraphobia, (d) generalized anxiety disorder, (e) obsessive-compulsive disorder, (f) separation anxiety disorder, and (g) fear of physical injury. Subscales are counted separately to produce scores pertinent to the specific sub-construct and to obtain an overall anxiety symptom score. Appropriate responses must fall between 0 (never) and 3 (always) points (25). To identify children with anxiety, we used a cutoff point $\geq 55$ for total score, as long as at least one subscale was altered (subscale score $\geq 84$ percentile). The questionnaire has been previously validated and translated into 20 languages including Spanish (29).

\section{Laboratory determinations}

Peripheral blood samples were obtained early in the morning after 8-10 h of fasting, centrifuged at $1006 \boldsymbol{g}$ to separate serum, and preserved at $-70^{\circ} \mathrm{C}$. Insulin and cortisol were determined by chemoluminiscence (Siemens Healthcare Diagnostic Products) and leptin and acylated ghrelin were determined with a magnetic beads-based immunoassay (Human Metabolic Hormone Bead Panel 
HMHE MAG-34K, EMD Millipore Corporation) using a MAGPIX microplate reader (Luminex Corporation, Austin, Texas, USA). The coefficients of variation were $\leq 10 \%$.

\section{Saliva cortisol response}

Children collected saliva samples at home for 2 consecutive days to calculate the cortisol response curve at baseline and at the end of the 8-week period. Parents and children were instructed to collect a saliva sample upon awakening while the child still in bed, another sample $30 \mathrm{~min}$ after waking up, and a third sample immediately before sleeping. Children were instructed to collect the first and second samples before eating, drinking, or brushing their teeth, and the night sample when already in bed and at least 20 min after taking some food or doing any physical activity. Each sample was collected and labeled in $2 \mathrm{~mL}$ polystyrene tubes using the passive drool method. Salivary cortisol was determined with an ELISA method (R\&D Systems). The coefficient of variation was $\leq 12 \%$. Three parameters were calculated: (i) the cortisol awakening response (CAR), obtained by subtracting awakening value from the 30-min value; (ii) Slope-1 (S1), calculated by subtracting awakening value from that before sleeping; and (iii) Slope-2 (S2), as the difference between the 30-min value and the sleeping value $(30,31)$. Values obtained on the first and second day were averaged.

\section{Statistical analysis}

STATA v.12.0 software was used for statistical analysis. A $P$-value of $\leq 0.05$ was considered statistically significant. Data are presented as mean \pm s.E. or as frequency as appropriate. Delta values of all parametric variables were calculated by subtracting final (time 8) from basal (time 0) values. A non-normal distribution was observed for most of the quantitative variables using the Shapiro-Wilk test; therefore, log-transformation was used for statistical analysis. Paired $t$-test, Student $t$-test, and $\chi^{2}$ analyses were used for inferences. Because of differences in sample sizes, we used the Levene test to discard different variances. Given that variances were not different $(P=0.198)$, we used Student $t$-test for equal variances to assess differences in the response to intervention.

\section{Results}

From 700 screened children, 206 were evaluated for eligibility. Sixty-three who met the selection criteria and

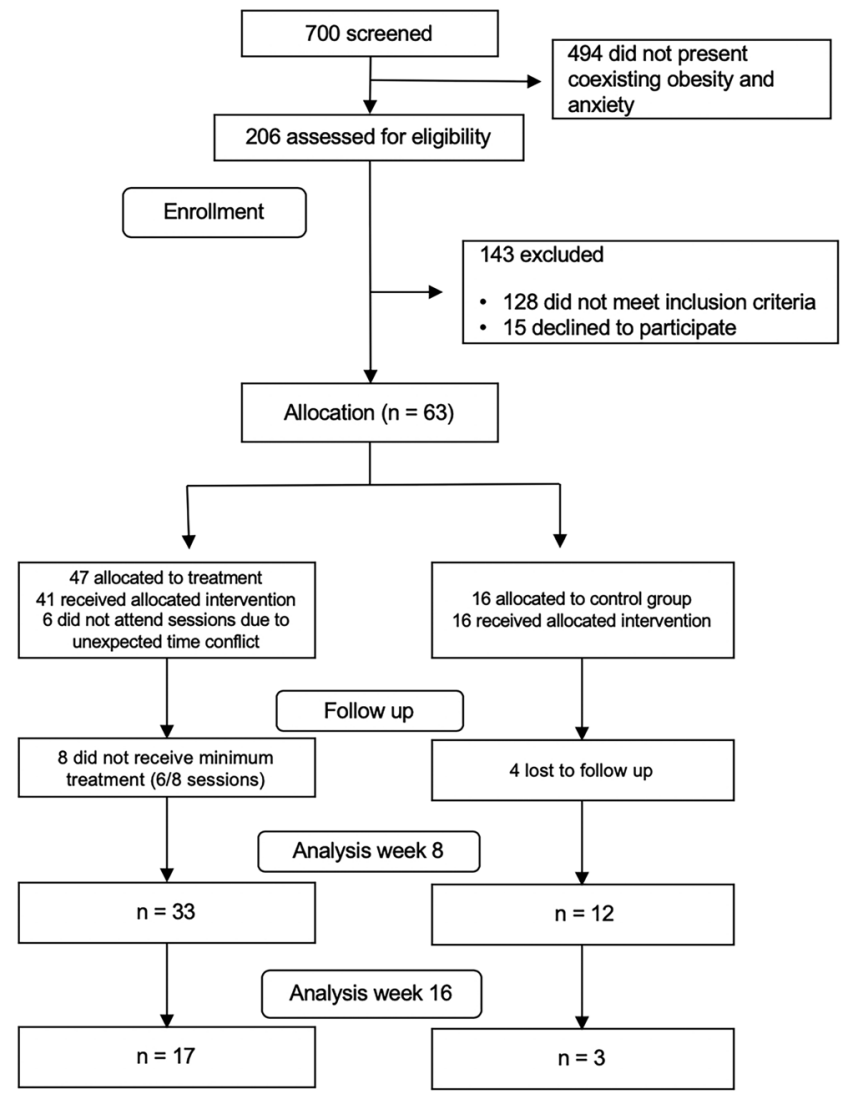

Figure 1

Flow diagram.

agreed to participate were enrolled, 47 in the MND-CNI group and 16 in the CNI group. Thirty-three MND-CNI and $12 \mathrm{CNI}$ children completed the 8-week intervention period. Anthropometry of $17 \mathrm{MND}-\mathrm{CNI}$ and three CNI children was assessed again at week 16 . The causes of subjects dropping out of the study were mainly parental time conflicts with the schedule of sessions, and children objecting to blood sampling (Fig. 1).

Anthropometric, biochemical, and psychological characteristics were comparable between groups attending the first and second phases $(P \geq 0.450)$. Therefore, both phases were analyzed together.

\section{Baseline}

Raw analysis confirmed that anthropometric and body fat measurements were above normal ranges, but the means of biochemical parameters were found to be within reference values $(24,32,33,34)$ (Table 1$)$.

By design, all included children had a Spence anxiety score $\geq 55$ points. The total mean and subscale scores were comparable between groups (Table 2). The most frequently

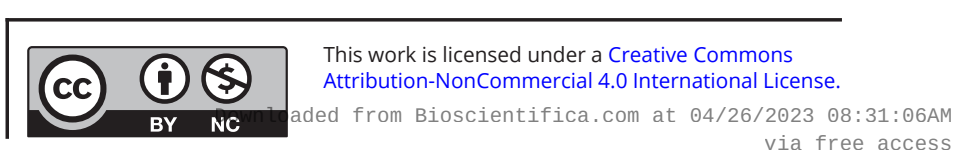


Table 1 Baseline anthropometric and biochemical characteristics of participants stratified by treatment.

\begin{tabular}{|c|c|c|c|c|}
\hline & MND-CNI $(n=33)$ & CNI $(n=12)$ & P-value & Reference values \\
\hline \multicolumn{5}{|c|}{ Count } \\
\hline Sex, female & 11 & 5 & & \\
\hline Puberty & 26 & 12 & & \\
\hline \multicolumn{5}{|c|}{ Mean \pm S.E. } \\
\hline Age, years & $11.3 \pm 0.28$ & $11.5 \pm 0.41$ & 0.584 & \\
\hline Weight, kg & $65.3 \pm 2.76$ & $66.2 \pm 4.2$ & 0.859 & \\
\hline Height, $\mathrm{cm}$ & $151.5 \pm 1.71$ & $154.5 \pm 2.60$ & 0.358 & \\
\hline BMI, z-score & $2.52 \pm 0.09$ & $2.35 \pm 0.19$ & 0.458 & $<1.5(24)$ \\
\hline Body fat, $\%$ & $42.7 \pm 0.88$ & $41.3 \pm 2.11$ & 0.979 & $<30(24)$ \\
\hline Insulin, $\mu \mathrm{U} / \mathrm{mL}$ & $12.1 \pm 1.40$ & $10.2 \pm 2.10$ & 0.468 & $<17(32)$ \\
\hline Ghrelin, pg/mL & $14.7 \pm 0.53$ & $12.9 \pm 0.44$ & 0.017 & $<23.32$ (33) \\
\hline Leptin, ng/mL & $14.8 \pm 1.48$ & $14.1 \pm 3.28$ & 0.434 & $<18(32)$ \\
\hline Serum cortisol, $\mu \mathrm{g} / \mathrm{dL}$ & $11.2 \pm 0.78$ & $8.84 \pm 0.72$ & 0.168 & $11.5 \pm 5.7(34)$ \\
\hline
\end{tabular}

Statistical analysis was conducted with Student $t$-test using log-transformed data. CNI: conventional nutrition intervention group; MND-CNI: mindfulness plus CNI.

altered subscales were 'separation anxiety disorder' (84.8 and $83.3 \%)$ and 'generalized anxiety disorder' (66.7 and 58\%) for MND-CNI and CNI, respectively.

Forty-nine children (40 MND-CNI and nine CNI) provided saliva samples to determine cortisol response. Comparison of this group with a group of college students with a proven stress-free status (35) revealed an elevated 30-min cortisol concentration in our children even if compared with the highest range of the non-stressed students (Fig. 2).

\section{End of 8-week follow-up}

Changes in anxiety scores were significantly different between groups; while a reduction in the total score in the MND-CNI group $(P<0.001)$ was observed, no changes were perceived in CNI children $(P=0.838)$. A detailed analysis demonstrated that all subscale scores decreased significantly in the MND-CNI group. In contrast, the 'agoraphobia and panic', 'separation anxiety', and 'social phobia' subscales increased significantly in the CNI group (Table 2). Accordingly, the proportion of children with altered subscales decreased in the MND-CNI group and increased in the CNI group $(P<0.05)$.

Likewise, significant reductions in BMI, body fat, and ghrelin were observed in the MND-CNI group, while these variables did not change in the CNI group (Table 3). In addition, the MND-CNI group exhibited a marginal decrease in serum cortisol $(P=0.071)$ compared to a significant increase in the CNI group $(P=0.016)$. Changes in serum ghrelin and cortisol were statistically different between groups (Fig. 3). Spence score total deltas correlated with BMI deltas $(r=0.551, P<0.001)$ and cortisol deltas $(r=0.316, P=0.041)$.
Saliva samples for the cortisol response curve at both basal and final times were available for $25 \mathrm{MND}-\mathrm{CNI}$ and four CNI children. Neither group showed any significant change in the cortisol response curve. CAR change was $0.63 \pm 1.10 \mu \mathrm{g} / \mathrm{dL}(P=0.480)$ for the MND-CNI group and $-1.06 \pm 0.76 \mu \mathrm{g} / \mathrm{dL}(P=0.900)$ for the CNI group.

\section{End of 16-week follow-up}

Seventeen MND-CNI and three CNI children attended the Research Unit at week 16 for anthropometric assessment. Since the number of CNI children who attended was insufficient for statistical analysis, we present only comparisons of weight, height, and BMI z-scores within the MND-CNI group. Body weight did not change during the 8-week intervention period $(-371 \pm 528 \mathrm{~g}, P=0.493)$ or at the end of the 16-week period $(1000 \pm 603 \mathrm{~g}, P=0.117)$. In contrast, significant increases in height were observed at both times ( $154 \pm 31$ and $234 \pm 41 \mathrm{~mm}$ respectively, $P<0.001$ ).

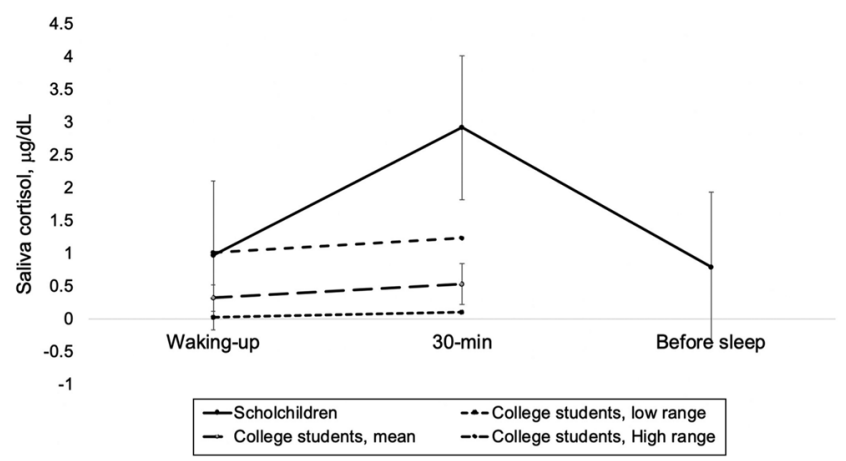

Figure 2

Salivary cortisol response curve of school children at baseline $(n=49)$, compared with the salivary cortisol response of non-stressed college students $(n=32)$.

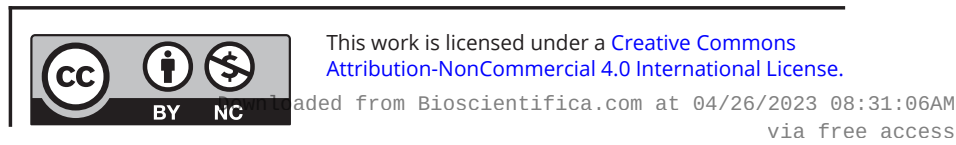




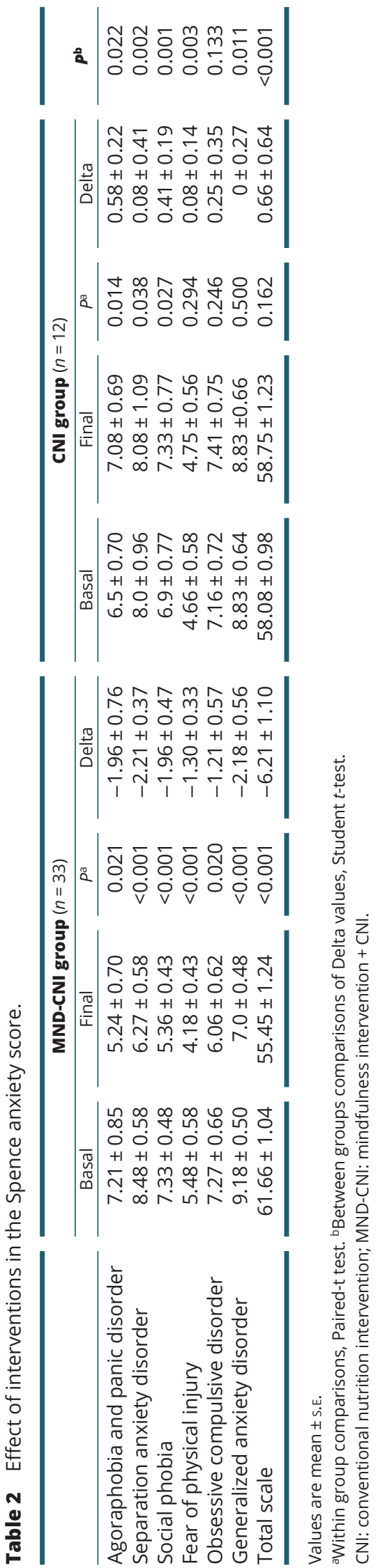

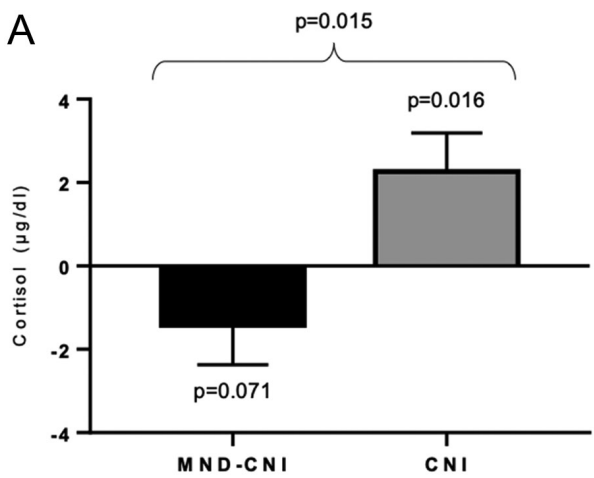

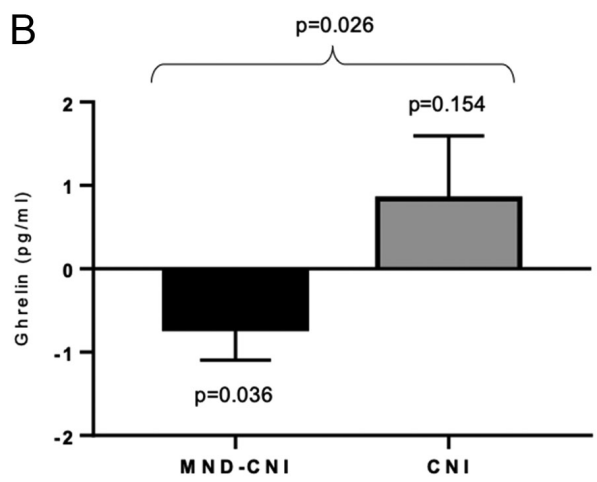

Figure 3

Deltas of cortisol, ghrelin, and BMI are presented. Statistical analysis was conducted with paired $t$-test and Student $t$-test as appropriate.

Thus, because BMI is a function of weight and height, BMI z-scores decreased significantly at the end of the 8 -week intervention period $\left(-0.12 \pm 0.04 \mathrm{~kg} / \mathrm{m}^{2}, P=0.004\right)$ and continued below the baseline value at week 16 $\left(-0.17 \pm 0.05 \mathrm{~kg} / \mathrm{m}^{2}, P=0.004\right)$ (Fig. 4).

\section{Discussion}

To our knowledge, this is the first study to investigate the usefulness of mindfulness as adjuvant treatment in pediatric obesity, and to simultaneously examine its effect on three outcomes: stress, appetite regulators, and body weight. Children who received the mindfulness intervention exhibited significant declines in anxiety scores, ghrelin, and BMI, as well as maginal decreases in serum cortisol. Moreover, the observed effect on BMI persisted beyond the period of intervention.

It is important to emphasize the probable effect of mindfulness on the stress imposed by a dietary regimen. In this study, both groups were exposed to dietary interventions for calorie restriction, but only the control group showed significant increases in some anxiety measures. This raises questions regarding the potentially

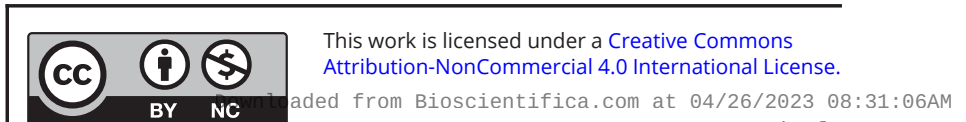




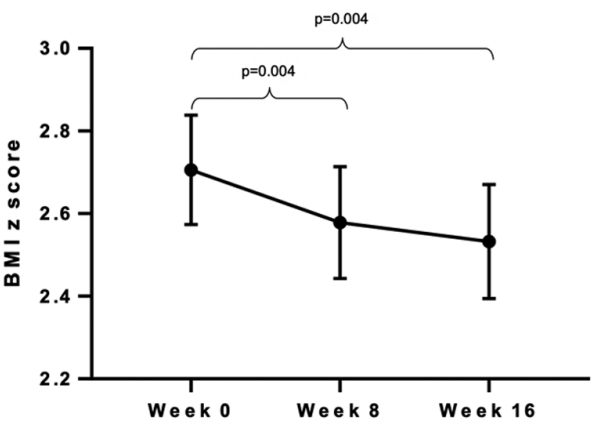

Figure 4

$\mathrm{BMI}$ of children who received the mindfulness intervention and completed 16-weeks follow-up $(n=17)$. Significant decreases were observed from basal to week 8 and from basal to week 16. Pared $t$-test was used for comparisons.

negative effect that stress may have on intentional weight loss in this population. Thus, in cases where the stress of engaging in dietary restriction might result in unsuccessful attempts at weight loss, our research supports the inclusion of mindfulness sessions as a possible method of counteracting anxiety in children engaged in calorie restriction strategies.

However, some limitations of our study merit consideration. We are aware that the study was statistically underpowered for the detection of differences between groups in the BMI response to intervention, because the sample size of the control group was smaller than the study design originally planned. Statistically, this is read only as a likelihood greater than 5\% (8\% in this case) that groups are truly different, but unfortunately it also put in doubt the confidence of our results. Nevertheless, we believe that the consistency in the results, such as a significant BMI reduction in the mindfulness group $(P=0.009$, Table 3), a sustained decrease in the subgroup who attended for the full 16 weeks (Fig. 4), and the significant correlation between changes in BMI and in anxiety, permits us to interpret our results as finding a beneficial effect of mindfulness sessions on the BMI of obese children with anxiety. Nonetheless, we recognize the need to confirm our result with a larger, balanced sample population.

Another point to discuss is that even though the study was planned as a randomized clinical trial, the study became an imbalanced design because the study was not blinded, as once parents received information about the two arms of the study, most of them decided to enrol only if assigned to the mindfulness group. In addition, at the end of the first phase of the study (at the finishing of the first group) we observed an undoubted improvement in the Spence anxiety score in the mindfulness group only, which made us consider it unethical to continue to assign children to the control group; we therefore assigned children to this group only if the parents were unable to attend the mindfulness sessions. Thus, because of parental self-selection, a systematic selection bias may have occurred, which may have affected the reliability of our results. Nevertheless, it is important to consider that BMI and cortisol were not different at baseline (Table 1), which suggests no selection bias; although we know that because of the small sample size in the control group, this lack of statistical power does not preclude the existence of a selection bias, we must remember that by design, children in both groups were all obese and all exhibited anxiety. Therefore, we are confident that there was no bias and that our interpretation of the results is accurate. Once last source of potential bias exists: the parents in each group may have had a different motivation regarding intervention. Those in the mindfulness group may have had much greater level of engagement with the intervention procedures, including the restricted diet.

Table 3 Effect of interventions in anthropometric and biochemical variables.

\begin{tabular}{|c|c|c|}
\hline & \multicolumn{2}{|c|}{ MND-CNI group $(n=33)$} \\
\hline & Delta & $P^{a}$ \\
\hline Weight, kg & $0.61 \pm 0.37$ & 0.113 \\
\hline Height, cm & $1.06 \pm 0.17$ & $<0.001$ \\
\hline $\mathrm{BMI}, \mathrm{kg} / \mathrm{m}^{2}$ & $-0.12 \pm 0.16$ & 0.009 \\
\hline BMI Z-score & $-0.07 \pm 0.03$ & 0.008 \\
\hline Body fat, $\%$ & $-1.28 \pm 0.25$ & $<0.001$ \\
\hline Insulin, $\mu \mathrm{U} / \mathrm{mL}$ & $3.14 \pm 2.33$ & 0.177 \\
\hline Ghrelin, pg/mL & $-0.71 \pm 0.37$ & 0.036 \\
\hline Leptin, ng/mL & $0.19 \pm 0.64$ & 0.326 \\
\hline Cortisol, $\mu \mathrm{g} / \mathrm{dL}$ & $-1.42 \pm 0.94$ & 0.071 \\
\hline
\end{tabular}

\begin{tabular}{|c|c|}
\hline \multicolumn{2}{|c|}{ CNI group $(n=12)$} \\
\hline Delta & $P^{a}$ \\
\hline $1.02 \pm 0.88$ & 0.136 \\
\hline $1.11 \pm 0.25$ & $<0.001$ \\
\hline$-0.05 \pm 0.09$ & 0.467 \\
\hline$-0.05 \pm 0.09$ & 0.276 \\
\hline$-1.24 \pm 0.91$ & 0.111 \\
\hline $0.11 \pm 1.82$ & 0.254 \\
\hline $0.83 \pm 0.75$ & 0.154 \\
\hline$-0.68 \pm 1.18$ & 0.276 \\
\hline $2.26 \pm 0.93$ & 0.016 \\
\hline
\end{tabular}

\begin{tabular}{c}
\hline \multicolumn{1}{c}{$\mathbf{b}$} \\
\hline 0.311 \\
0.563 \\
0.081 \\
0.383 \\
0.527 \\
0.571 \\
0.026 \\
0.271 \\
0.015 \\
\hline
\end{tabular}

Values are mean \pm S.E.

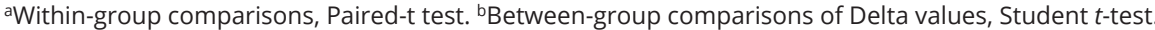

CNI: conventional nutrition intervention; MND-CNI: mindfulness intervention + CNI. Statistical analyses were conducted with log-transformed data.

https://ec.bioscientifica.com

https://doi.org/10.1530/EC-19-0461 (c) 2020 The authors Published by Bioscientifica Ltd

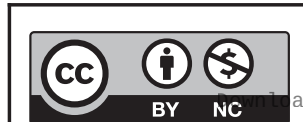

This work is licensed under a Creative Commons Attribution-NonCommercial 4.0 International License. ded from Bioscientifica.com at 04/26/2023 08:31:06AM via free access 
Nevertheless, even if the beneficial results observed in the MND-CNI group are the consequence of the parental engagement with the mindfulness program, we think that this remains a positive outcome from this study.

It is also important to clarify why we compared the baseline salivary cortisol response curve of our children with that of a stress-free sample of students (35). Since we found serum cortisol between normal ranges at baseline (Table 1,35), it could be interpreted that our children were not stressed. However, salivary cortisol was high when compared with that of non-stressed students (Fig. 2), ratifying the status of stress at baseline and coinciding with anxiety score data. Nevertheless, no effect on the salivary cortisol response curve was observed, as reported by others $(18,22)$. It is possible that mindfulness did not affect the cortisol response, but it is also likely that unreported mistakes committed in the process of obtaining the saliva specimens affected the results, for instance, in the timing of sampling or in any of the other aspects that are required for an appropriate technique, as suggested by Smyth and coworkers (36). Unfortunately, while we provided instructions for sampling, we did not monitor the adequacy of the saliva sampling procedure. Nonetheless, we think that such behavior in the cortisol response does not necessarily reflect a lack of effect on stress, given that improvements in anxiety scores and serum cortisol were observed.

We are aware that the scientific literature is full of different mindfulness programs. Such heterogeneity in the intervention tool may be, at least partially, responsible for the controversial results among studies. Thus, we recognize that our results reflect only the mindfulness program of the 'Escuela Española de Desarrollo Transpersonal' (EEDT). An important strength of the EEDT program is that it includes mindfulness for stress reduction tools together with some strategies to promote conscious eating (28), but we recognize that no formal studies have been conducted to test its efficacy. Other strong points are that we provided mindfulness sessions to the parent-child dyad to improve the efficacy of the intervention, as has been previously suggested (37), and also that the mindfulness intervention was delivered by personnel previously trained and certified by the EEDT.

Regarding the effect on appetite-regulator hormones, ghrelin concentration decreased in the MND-CNI group, but not in the CNI group, suggesting that the effect of mindfulness on BMI may be exerted through influence on appetite or eating behavior, as suggested by others $(38,39$, $40,41)$. This is relevant because, physiologically, ghrelin is an appetite-stimulating hormone that increases when energy supply is low, but also seems to drive hedonic food consumption. Thus, as stress also induces hedonic eating, it is probable that this hormone also mediates the conduct of eating under stress (13). Our results are congruent with this role of ghrelin on appetite, because a decline in ghrelin concentration was observed after the mindfulness intervention as reported previously $(42,43)$.

Finally, we are aware that the magnitude of the reduction in BMI we found may not be remarkable. However, considering that an adequate weight loss for children at this age should not be greater than $10 \%$ of their basal body weight in 6 months (44), we believe that the changes we observed in BMI in a short period may be biologically significant and relevant enough to consider mindfulness as a suitable approach to support longer-term weight loss interventions in children. In fact, our result is in line with that reported in a recent paper that proposes a 0.6 decrease in BMI z-score as biologically significant, since it is associated with at least $5 \%$ reduction in percentage body fat (45).

In conclusion, our results suggest that mindfulness is a promising tool when used as an adjunctive therapy for childhood obesity, either because of its potential to decrease stress or because it could counteract the stress associated with a restrictive dietary regimen. However, we recognize that our findings need to be confirmed with a larger, balanced sample population.

\section{Declaration of interest}

The authors declare that there is no conflict of interest that could be perceived as prejudicing the impartiality of the research reported.

\section{Funding}

This work was supported by the IMSS National Research Comission: (grant number FIS/IMSS/PROT/G17-2/1737). Funder was not involved in the manuscript writing, editing, approval, or decision to publish it.

\section{References}

1 Gregg EW \& Shaw JE. Global health effects of overweight and obesity. New England Journal of Medicine 2017377 80-81. (https://doi. org/10.1056/NEJMe1706095)

2 Farpour-Lambert NJ, Baker JL, Hassapidou M, Holm JC, Nowicka P, O’Malley G \& Weiss R. Childhood obesity is a chronic disease demanding specific health care-a position statement from the Childhood Obesity Task Force (COTF) of the European Association for the Study of Obesity (EASO). Obesity Facts 20158 342-349. (https://doi.org/10.1159/000441483)

3 Yanovski AJ. Pediatric obesity. An introduction. Appetite 201593 3-12. (https://doi.org/10.1016/j.appet.2015.03.028)

4 Llewellyn C, Carnell S \& Wardle J. Eating behavior and weight in children. Epidemiology of Obesity in Children and Adolescents 201125 455-482. 
5 Rutters F, La Fleur S, Lemmens S, Born J, Martens M \& Adam T. The hypothalamic-pituitary-adrenal axis, obesity, and chronic stress exposure: foods and HPA axis. Current Obesity Reports $2012 \mathbf{1}$ 199-207. (https://doi.org/10.1007/s13679-012-0024-9)

6 Dallman MF. Stress-induced obesity and the emotional nervous system. Trends in Endocrinology and Metabolism 201021 159-165. (https://doi.org/10.1016/j.tem.2009.10.004)

7 MacCoon DG, Imei ZE, Rosenkranz MA, Sheftel JG, Weng HY, Sullivan JC, Bonus KA, Stoney CM, Salomons TV, Davidson RJ, et al. The validation of an active control intervention for mindfulness based stress reduction (MBSR). Behaviour Research and Therapy 2012 50 3-12. (https://doi.org/10.1016/j.brat.2011.10.011)

8 Ludwig DS \& Kabat-Zinn J. Mindfulness in medicine. JAMA 2008300 1350-1352. (https://doi.org/10.1001/jama.300.11.1350)

9 Kabat-Zinn J. The stress reduction clinic. Mindfulness 20167 775-776. (https://doi.org/10.1007/s12671-016-0503-2)

10 Daubenmier J, Moran PJ, Kristeller J, Acree M, Bacchetti P, Kemeny ME, Dallman M, Lustig RH, Grunfeld C, Nixon DF, et al. Effect of a mindfulness-based weight loss intervention in adults with obesity: a randomized clinical trial. Obesity 201624 794-804. (https://doi.org/10.1002/oby.21396)

11 Pascoe MC, Thompson DR, Jenkins ZM \& Ski CF. Mindfulness mediates the physiological markers of stress: systematic review and meta-analysis. Journal of Psychiatric Research 201795 156-178. (https://doi.org/10.1016/j.jpsychires.2017.08.004)

12 Shomaker LB, Bruggink S, Pivarunas B, Skoranski A, Foss J, Chaffin E, Dalager S, Annameier S, Quaglia J, Brown KW, et al. Pilot randomized controlled trial of a mindfulness-based group intervention in adolescent girls at risk for type 2 diabetes with depressive symptoms. Complementary Therapies in Medicine 201732 66-74. (https://doi. org/10.1016/j.ctim.2017.04.003)

13 Buss J, Havel PJ, Epel E, Lin J, Blackburn E \& Daubenmier J. Associations of ghrelin with eating behaviors, stress, metabolic factors, and telomere length among overweight and obese women: preliminary evidence of attenuated ghrelin effects in obesity? Appetite 201476 84-94. (https://doi.org/10.1016/j.appet.2014.01.011)

14 Asadollahi T, Khakpour S, Ahmadi F, Seyedeh L, Tahami MS, Matoo S $\&$ Bermas H. Effectiveness of mindfulness training and dietary regime on weight loss in obese people. Journal of Medicine and Life 20158 114-124.

15 Mason AE, Epel ES, Aschbacher K, Lustig RH, Acree M, Kristeller J, Cohn M, Dallman M, Moran PJ, Bacchetti P, et al. Reduced rewarddriven eating accounts for the impact of a mindfulness-based diet and exercise intervention on weight loss: data from the SHINE randomized controlled trial. Appetite 2016100 86-93. (https://doi. org/10.1016/j.appet.2016.02.009)

16 Goyal M, Singh S, Sibinga EM, Gould NF, Rowland-Seymour A, Sharma R, Berger Z, Sleicher D, Maron DD, Shihab HM, et al. Meditation programs for psychological stress and wellbeing: a systematic review and meta-analysis. JAMA Internal Medicine 2014174 357-368. (https://doi.org/10.1001/ jamainternmed.2013.13018)

17 Klatt MD, Buckworth J \& Malarkey WB. Effects of low-dose mindfulness-based stress reduction (MBSR-ld) on working adults. Health Education and Behavior 200936 601-614. (https://doi. org/10.1177/1090198108317627)

18 Daubenmier J, Hayden D, Chang V \& Epel E. It's not what you think, it's how you relate to it: dispositional mindfulness moderates the relationship between psychological distress and the cortisol awakening response. Psychoneuroendocrinology 201448 11-18. (https://doi.org/10.1016/j.psyneuen.2014.05.012)

19 Camilleri GM, Méjean C, Bellisle F, Hercberg S \& Péneau S. Association between mindfulness and weight status in a general population from the NutriNet-Santé Study. PLoS ONE 201510 e0127447. (https://doi.org/10.1371/journal.pone.0127447)
20 Stanton MV, Matsuura J, Fairchild JK, Lohnberg JA \& Bayley PJ. Mindfulness as a weight loss treatment for veterans. Frontiers in Nutrition 20163 30. (https://doi.org/10.3389/fnut.2016.00030)

21 Annameier SK, Kelly NR, Courville AB, Tanofsky-Kraff M, Yanovski JA \& Shomaker LB. Mindfulness and laboratory eating behavior in adolescent girls at risk for type 2 diabetes. Appetite 2018125 48-56. (https://doi.org/10.1016/j.appet.2018.01.030)

22 Skoranski A, Kelly NR, Radin RM, Thompson KA, Galescu O, Demidowich AP, Brady SM, Chen KY, Tanofsky-Kraff M, Yanovski JA, et al. Relationship of mindfulness to distress and cortisol response in adolescent girls at-risk for type 2 diabetes. Journal of Child and Family Studies 201827 2254-2264. (https://doi.org/10.1007/s10826-0181065-9)

23 Daubenmier J, Kristeller J, Hecht FM, Meninger N, Kuwata M, Jhaveri K, Lustig RH, Kemeny M, Karan L \& Epel E. Mindfulness intervention for stress eating to reduce cortisol and abdominal fat among overweight and obese women: an exploratory randomized controlled study. Journal of Obesity 20112011 651936. (https://doi. org/10.1155/2011/651936)

24 Center for Disease Control (CDC). Acerca del índice de masa corporal para niños y adolescentes [About child \& teen BMI]. Atlanta GA, USA: CDC, 2015. (available at: https://www.cdc.gov/healthyweight/ spanish/assessing/bmi/childrens_bmi/acerca_indice_masa_corporal_ ninos_adolescentes.html)

25 Spence SH, Barrett PM \& Turner CM. Psychometric properties of the Spence Children's Anxiety Scale with young adolescents. Journal of Anxiety Disorders 200317 605-625. (https://doi.org/10.1016/s08876185(02)00236-0)

26 Saghaei M. Random allocation software for parallel group randomized trials. BMC Medical Research Methodology 2004426. (https://doi.org/10.1186/1471-2288-4-26)

27 Joint WHO/FAO Expert Consultation. Diet, Nutrition and the Prevention of Chronic Diseases, pp. 54-60. Geneva, Switzerland: World Health Organization, 2002.

28 Escuela Española de Desarrollo Transpersonal. Fundación para la Educación y el Desarrollo Transpersonal. Programa de Educación Mindfulness Transpersonal para Centros Educativos CENCORE. Madrid, Spain: EDT, 2018. (available at: https://escuelatranspersonal.com)

29 Hernández L, Bermúdez G, Spence S, González M, Martínez J, Aguilar J \& Gallegos J. Versión en español de la Escala de Ansiedad para Niños de Spence (SCAS). Revista Latinoamericana de Psicología 201042 13-24.

30 Adam EK \& Kumari M. Assessing salivary cortisol in large-scale, epidemiological research. Psychoneuroendocrinology 200934 1423-1436. (https://doi.org/10.1016/j.psyneuen.2009.06.011)

31 Stalder T, Kirschbaum C, Kudielka BM, Adam EK, Pruessner JC, Wüst S, Dockray S, Smyth N, Evans P, Hellhammer DH, et al. Assessment of the cortisol awakening response: expert consensus guidelines. Psychoneuroendocrinology 201663 414-432. (https://doi. org/10.1016/j.psyneuen.2015.10.010)

32 Endocrinology expected values and S.I. unit conversion tables. Calabasas Hills, CA, USA: Endocrine Sciences LabCorp. (available at: https://www.endocrinesciences.com/).

33 Andarini S, Kangsaputra FB \& Handayani D. Pre- and postprandial acylated ghrelin in obese and normal weight men. Asia Pacific Journal of Clinical Nutrition 201726 S85-S91. (https://doi.org/10.6133/ apjcn.062017.s5)

34 Eyal O, Limor R, Oren A, Schachter-Davidov A, Stern N \& Weintrob N. Establishing normal ranges of basal and ACTHstimulated serum free cortisol in children. Hormone Research in Paediatrics 201686 94-99. (https://doi.org/10.1159/000447946)

35 Chong LS, Thai M, Cullen KR, Lim KO \& Klimes-Dougan B. Cortisol awakening response, internalizing symptoms, and life satisfaction in emerging adults. International Journal of Molecular Sciences $2017 \mathbf{1 8}$ E2501. (https://doi.org/10.3390/ijms18122501) https://ec.bioscientifica.com https://doi.org/10.1530/EC-19-0461 (c) 2020 The authors Published by Bioscientifica Ltd

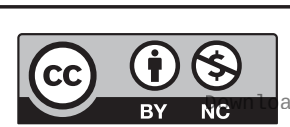

This work is licensed under a Creative Commons Attribution-NonCommercial 4.0 International License. ded from Bioscientifica com at 04/26/2023 08:31:06AM 
36 Smyth N, Thorn L, Hucklebridge F, Evans P \& Clow A. Detailed time course of the cortisol awakening response in healthy participants. Psychoneuroendocrinology 201562 200-203. (https://doi. org/10.1016/j.psyneuen.2015.08.011)

37 Jastreboff AM, Chaplin TM, Finnie S, Savoye M, StultsKolehmainen M, Silverman WK \& Sinha R. Preventing childhood obesity through a mindfulness-based parent stress intervention: a randomized pilot study. Journal of Pediatrics 2018202 136.e1-142.e1. (https://doi.org/10.1016/j.jpeds.2018.07.011)

38 O'Reilly GA, Cook L, Spruijt-Metz D \& Black DS. Mindfulness-based interventions for obesity-related eating behaviours: a literature review. Obesity Reviews 201415 453-461. (https://doi.org/10.1111/obr.12156)

39 Katterman SN, Kleinman BM, Hood MM, Nackers LM \& Corsica JA. Mindfulness meditation as an intervention for binge eating, emotional eating, and weight loss: a systematic review. Eating Behaviors 201415 197-204. (https://doi.org/10.1016/j. eatbeh.2014.01.005)

40 Pivarunas B, Kelly NR, Pickworth CK, Cassidy O, Radin RM, Shank LM, Vannucci A, Courville AB, Chen KY, Tanofsky-Kraff M, et al. Mindfulness and eating behavior in adolescent girls at risk for type 2 diabetes. International Journal of Eating Disorders 201548 563-569. (https://doi.org/10.1002/eat.22435)
41 Corsica J, Hood MM, Katterman S, Kleinman B \& Ivan I. Development of a novel mindfulness and cognitive behavioral intervention for stress-eating: a comparative pilot study. Eating Behaviors 201415 694-699. (https://doi.org/10.1016/j. eatbeh.2014.08.002)

42 Briggs DI, Lockie SH, Wu Q, Lemus MB, Stark R \& Andrews ZB. Calorie-restricted weight loss reverses high-fat diet-induced ghrelin resistance, which contributes to rebound weight gain in a ghrelindependent manner. Endocrinology 2013154 709-717. (https://doi. org/10.1210/en.2012-1421)

43 Briggs DI, Enriori PJ, Lemus MB, Cowley MA \& Andrews ZB. Diet-induced obesity causes ghrelin resistance in arcuate NPY/ AgRP neurons. Endocrinology 2010151 4745-4755. (https://doi. org/10.1210/en.2010-0556)

44 Wei C, Candler T, Crowne E \& Hamilton-Shield JP. Interval outcomes of a lifestyle weight-loss intervention in early adolescence. Children 20185 E77. (https://doi.org/10.3390/children5060077)

45 Birch L, Perry R, Hunt LP, Matson R, Chong A, Beynon R \& Shield JP. What change in body mass index is associated with improvement in percentage body fat in childhood obesity? A metaregression. BMJ Open 20199 e028231. (https://doi.org/10.1136/ bmjopen-2018-028231)

Received in final form 13 December 2019

Accepted 14 January 2020
This work is licensed under a Creative Commons Attribution-NonCommercial 4.0 International License. ded from Bioscientifica.com at 04/26/2023 08:31:06AM via free access 